\title{
Article \\ First Experiences with Newborn Screening for Congenital Hypothyroidism in Ulaanbaatar, Mongolia
}

\author{
Altantuya Tsevgee ${ }^{1}$, Khishigjargal Batjargal ${ }^{1,2}$, Tsolmon Munkhchuluun ${ }^{3}{ }^{\mathbb{D}}$, Naranchimeg Khurelbaatar ${ }^{4}$, \\ Gerelmaa Nansal ${ }^{4}$, Oyun-Erdene Bulgan ${ }^{5}$, Sumberzul Nyamjav ${ }^{6}{ }^{\mathbb{D}}$, Gerelmaa Zagd ${ }^{1}$ \\ and Erdenetuya Ganbaatar $1, * \mathbb{D}$
}

1 Department of Pediatrics, School of Medicine, Mongolian National University of Medical Sciences, Ulaanbaatar 14210, Mongolia; ts.altantuya1127@gmail.com (A.T.); khishigjarga10802@gmail.com (K.B.); gerelmaa@mnums.edu.mn (G.Z.)

2 Department of Pediatrics, Jichi Medical University, 3311-1 Yakushiji, Shimotsuke-shi, Tochigi 329-0498, Japan

3 Department of Health Promotion and Disease Prevention, National Center for Public Health, Ulaanbaatar 13381, Mongolia; tsolmon01@gmail.com

4 Children's Hospital, National Center for Maternal and Child Health, Bayangol District, Ulaanbaatar 16060, Mongolia; kh_naraa08@yahoo.com (N.K.); Ngerelmaa@yahoo.com (G.N.)

5 Screening Diagnostic Reference Center, Bayangol District, Ulaanbaatar 16091, Mongolia; oyuda_b@yahoo.com

6 Graduate School, Mongolian National University of Medical Sciences, Ulaanbaatar 14210, Mongolia; sumberzul@mnums.edu.mn

* Correspondence: erdenetuya@mnums.edu.mn; Tel.: +976-9917-5770

check for updates

Citation: Tsevgee, A.; Batjargal, K.; Munkhchuluun, T.; Khurelbaatar, N.; Nansal, G.; Bulgan, O.-E.; Nyamjav, S.; Zagd, G.; Ganbaatar, E. First Experiences with Newborn Screening for Congenital Hypothyroidism in Ulaanbaatar, Mongolia. Int. J. Neonatal Screen. 2021, 7, 29. https:// doi.org/10.3390/ijns7020029

Academic Editor: Natasha Heather

Received: 2 May 2021

Accepted: 3 June 2021

Published: 7 June 2021

Publisher's Note: MDPI stays neutral with regard to jurisdictional claims in published maps and institutional affiliations.

Copyright: (c) 2021 by the authors. Licensee MDPI, Basel, Switzerland. This article is an open access article distributed under the terms and conditions of the Creative Commons Attribution (CC BY) license (https:/ / creativecommons.org/licenses/by/ $4.0 /)$.
Abstract: Congenital hypothyroidism $(\mathrm{CH})$ is among the most common conditions leading to intellectual disability, which can be prevented by early detection through newborn screening (NBS). In Mongolia, a regional screening program for $\mathrm{CH}$ was launched in 2000, which was supported by the International Atomic Energy Agency (IAEA) for the Asia Pacific Region. In our present study, a total of 23,002 newborns from nine districts in Ulaanbaatar were screened between 2012 and 2020, by the measurement of the thyroid-stimulating hormone (TSH) from dried blood spots, sampled 24 to $72 \mathrm{~h}$ after birth. The level of TSH was measured by the DELFIA assay. The overall $\mathrm{CH}$ prevalence confirmed at birth was 1/2091. The female-to-male ratio for $\mathrm{CH}$ cases was 1.8:1. The majority of patients were asymptomatic $(72.7 \%$ of $\mathrm{CH}$ cases); umbilical hernia and cold or mottled skin were reported symptoms in patients with $\mathrm{CH}(27.3 \%)$. Thyroid dysgenesis (hypoplasia and agenesis) was the most common etiology, with a total of nine cases $(81.8 \%)$ out of the eleven patients. The lapse between the birth date and the initiation of L-thyroxine treatment in $\mathrm{CH}$-positive children was lower than 15 days in $63.64 \%$ of cases or 15 to 30 days in $36.36 \%$ of children. Further research is required to expand the screening coverage for $\mathrm{CH}$ in Mongolia.

Keywords: congenital hypothyroidism; neonatal screening; blood spot test; filter paper

\section{Introduction}

Congenital hypothyroidism $(\mathrm{CH})$ is among the most common neonatal endocrine disorders and the few preventable causes of severe neurological and psychiatric impairment $\mathrm{CH}$ affects approximately one in 3000 to 4000 live births worldwide [1,2]. Recent reports suggest that the prevalence of $\mathrm{CH}$ is increasing; in particular, the prevalence of $\mathrm{CH}$ among Asian infants is higher than other ethnicities [3,4]. Most neonates born with $\mathrm{CH}$ have normal appearance and no detectable physical signs. Asymptomatic $\mathrm{CH}$ results in severe neurodevelopmental impairment if treatment is delayed [5]. Therefore, NBS is mandatory to screen neonates for $\mathrm{CH}$ for early diagnosis and treatment.

Over the last 40 years, NBS programs have been established in most developed countries, measuring thyroid-stimulating hormone (TSH) and thyroxine (T4) in dried blood spots, and have allowed the early detection of $\mathrm{CH}$ [6]. However, NBS programs have not been able to be implemented in developing countries, including Mongolia. There 
is increased awareness of the frequency and importance of severe neurodevelopmental deficits that result from delayed diagnosis [7]. Among the Mongolian population, the prevalence and clinical forms of $\mathrm{CH}$ are studied insufficiently. In the past two decades, only one study conducted in Mongolia found the prevalence of $\mathrm{CH}$ of 1 in 1892 live births [8]. There have been no other studies that have investigated the prevalence rate and clinical forms of $\mathrm{CH}$ in Mongolia since 2002.

The aim of this study was to assess the prevalence of $\mathrm{CH}$ in Ulaanbaatar, Mongolia between 2012 and 2020.

\section{Materials and Methods}

\subsection{Patient Population}

From 2012 to 2020, a total of 23,002 neonates were screened in Ulaanbaatar for $\mathrm{CH}$. During this period, a total of nine districts joined the screening program, involving a maximum of six maternity hospitals (out of seven in Ulaanbaatar) (Figure 1). Based on the goal, one maternity hospital was excluded from our study due to referred mothers from provinces. The suspected $\mathrm{CH}$ neonates were recalled, confirming $\mathrm{CH}$. $\mathrm{CH}$ was diagnosed with a report of thyroid ultrasound and the results of laboratory tests. Ultrasonography of the thyroid gland was performed during the first month of life.

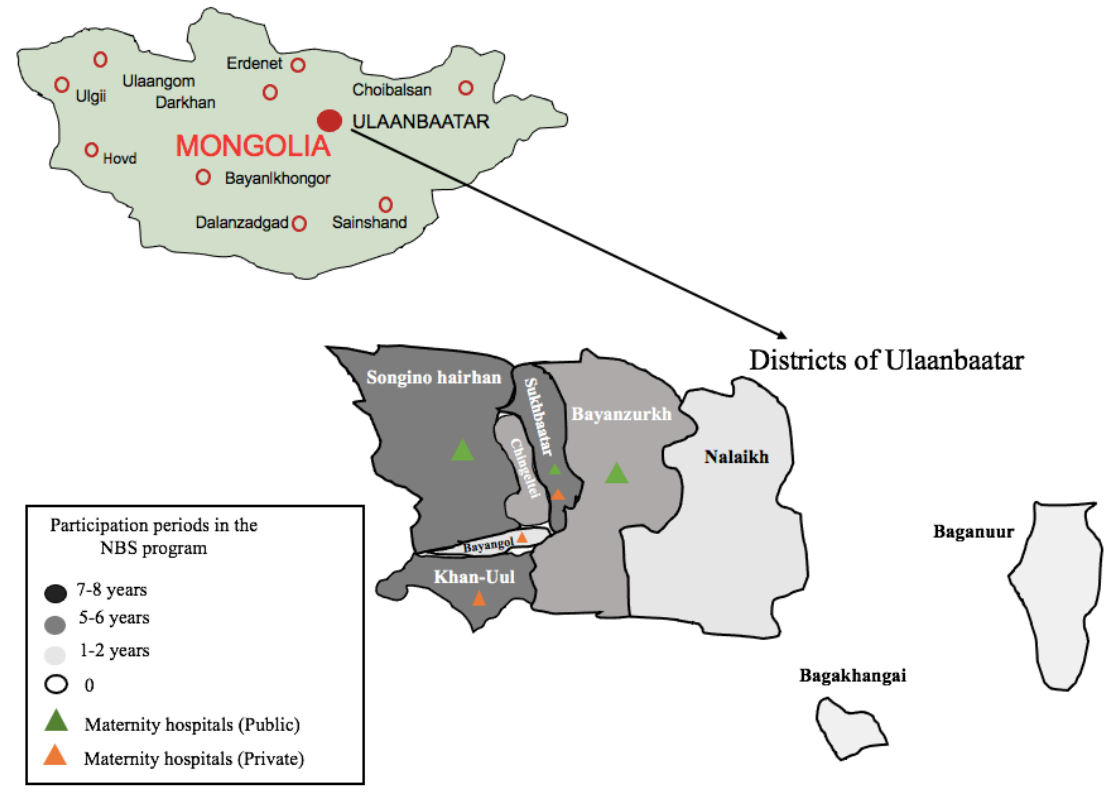

Figure 1. Participation periods (years) for the nine districts of Ulaanbaatar; six maternity hospitals are involved in the NBS program for $\mathrm{CH}$. The map shows, in shades of light grey, dark grey, and black, the nine districts (out of nine in Ulaanbaatar); colored triangles show the six maternity hospitals (out of seven in Ulaanbaatar).

\subsection{Newborn Screening for $\mathrm{CH}$}

The newborn screening for $\mathrm{CH}$ was based on the measurement of thyroid-stimulating hormone (TSH) in dried blood spots on filter paper specimens. Dried blood samples on filter paper were collected from newborns born in Ulaanbaatar at 24 to $72 \mathrm{~h}$ of age from public and private maternity hospitals by the Screening Diagnostic Reference Center. According to the guidance of NBS developing programmes from IAEA [9] and the Centers for Disease Control and Prevention (CDC) [10], we evaluated valid or invalid blood specimens on filter paper before screening. Thus, inadequately collected blood samples or invalid blood specimens for TSH determination were excluded and new samples were collected by trained nurses at the maternity hospitals. A time-resolved fluoroimmunoassay was used to measure the TSH concentration in the dry blood spot specimen using a DELFIA assay (AutoDELFIA kit of neonatal human TSH dry blood, Perkin Elmer, Turku, Finland). 
A cut-off value of $20 \mathrm{mIU} / \mathrm{L}$ was used for the whole blood TSH in dried blood spots during this period. Since a range of cut-offs from 10 to $30 \mathrm{mIU} / \mathrm{L}$ were used by different programs and countries [11-13], a trial was conducted from 2012 to 2015 to define the most efficient threshold for our conditions. When the TSH value on the filter paper was $<20 \mathrm{mIU} / \mathrm{L}$, it was considered negative, and no further action was pursued. TSH values $\geq 20 \mathrm{mIU} / \mathrm{L}$ on the filter paper were considered positive for $\mathrm{CH}$, and a new dried blood specimen was requested for the second screening. In the second screening, if the TSH values were still $\geq 16 \mathrm{mIU} / \mathrm{L}$ in dried blood spots, venous blood was collected from the infant to analyze the total thyroxine (tT4) and TSH levels. Serum hormone TSH and tT4 were measured by an immune-enzymatic sandwich assay (ELISA) commercial kit (Roche Diagnostic, Mannheim, Germany). The cut-off venous tT4 concentration was $66 \mathrm{nmol} / \mathrm{L}$ (The National Center for Maternal and Child Health reference values, Ulaanbaatar, Mongolia). When venous TSH concentrations were $>10 \mathrm{mIU} / \mathrm{L}$ and the $\mathrm{tT} 4$ concentrations were $<66 \mathrm{nmol} / \mathrm{L}$, the infant was considered to have $\mathrm{CH}$ and was treated with L-thyroxine of $10 \mu \mathrm{g} / \mathrm{kg}$ every day. When the serum results (TSH and tT4) were within normal ranges, the infant was considered as false-positive. When TSH serum concentrations were between 12 and $16 \mathrm{mIU} / \mathrm{L}$ (gray zone) and the tT4 concentrations were normal, the patient was followed up every 15 days and considered as having subclinical hypothyroidism. A flowchart of the diagnosis of $\mathrm{CH}$ is shown in Figure 2.

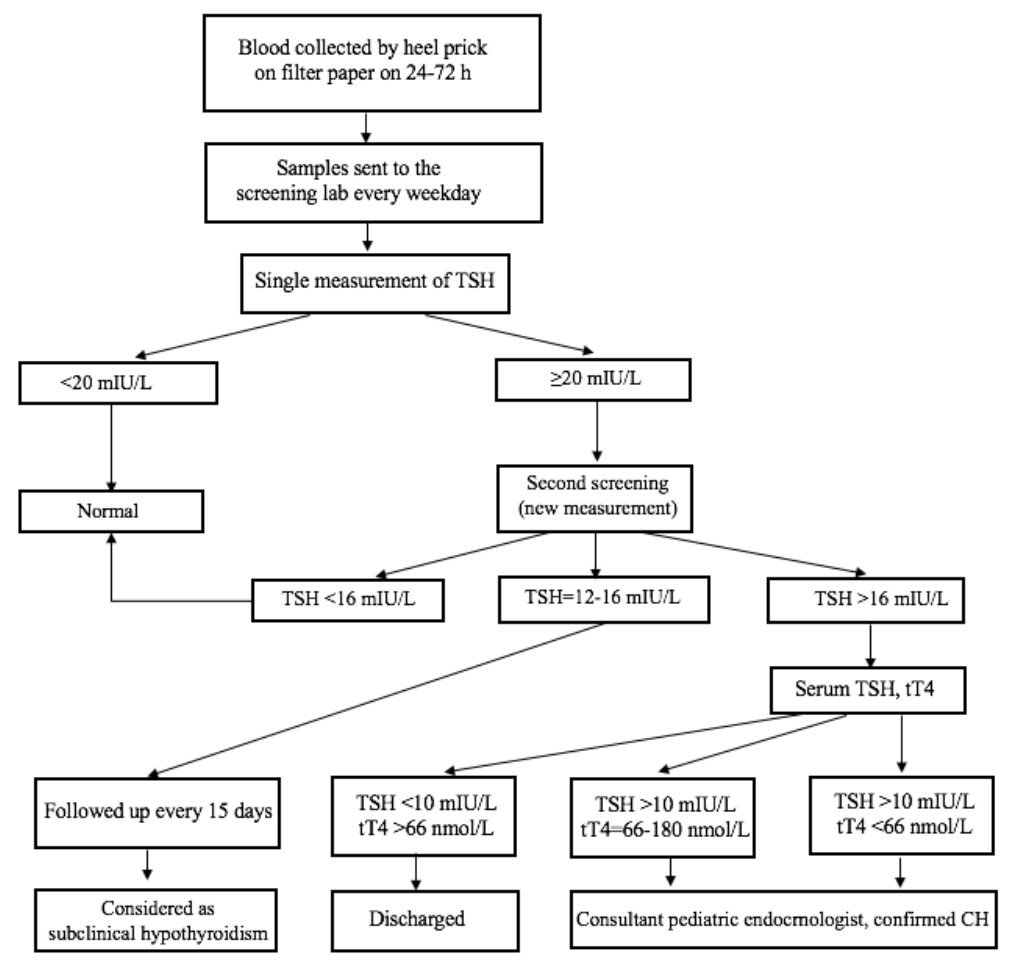

Figure 2. A flowchart of the diagnosis of $\mathrm{CH}$; TSH-thyroid stimulating hormone, tT4-total thyroxine in serum.

\subsection{Statistical Methods}

All information was initially entered into a data collection sheet and then analyzed using Stata version 16 (StataCorp.2019. Stata Statistical Software: Release 16. College Station, TX: StataCorp LLC, College Station, TX, USA). Descriptive statistics, including frequencies, percentages, means, and standard deviations (SDs), median, and range were calculated to characterize the demographic and clinical data. The prevalence of $\mathrm{CH}$ was calculated using the total number of infants who were screened as a denominator and the total number of cases as the numerator. 


\section{Results}

From 2012 to 2020, a total of 23,002 newborns were screened and covered over $6.7 \%$ of the total neonatal population (approximately 40,000 births per year in Ulaanbaatar). The demographic characteristics of the population covered by the Mongolian National NBS program for $\mathrm{CH}$ and the results of the program are summarized in Table 1 . The first year of the program covered three maternity hospitals from nine districts in Ulaanbaatar. The program expanded from three to six maternity hospitals (from a total of seven) of Ulaanbaatar in its eight years of existence, mainly in the central regions (Figure 1). The number of neonates screened for $\mathrm{CH}$ increased approximately two- to threefold in several years, particularly in 2017 and 2019, but it was not consistent during the study period (Table 1). However, when the total number of children born in Ulaanbaatar is considered, only $6.7 \%$ benefited from screening during the period of 2012 to 2020 . In the study period, 87 children were suspected as having $\mathrm{CH}$ (total positive children at screening dried blood spot TSH in $\geq 20 \mathrm{mIU} / \mathrm{L}$ ), representing an average of $0.4 \%$ of all of the samples analyzed. Inadequately collected blood samples, unsuitable for TSH determination, accounted for $3.0 \%$ on average by the guidance of IAEA and CDC $[9,10]$. Experience gained in blood sampling led to a decrease from the initial $5.3 \%$ to $1.6 \%$ more recently.

Table 1. Characteristics and results of the NBS for CH in Ulaanbaatar (2012 to 2020).

\begin{tabular}{|c|c|c|c|c|c|c|c|c|c|c|}
\hline Year & $\begin{array}{c}2012 \\
\text { (between July } \\
\text { and December) }\end{array}$ & 2013 & 2014 & 2015 & 2016 & 2017 & 2018 & 2019 & 2020 & Total/Average \\
\hline \multicolumn{11}{|c|}{ DEMOGRAPHY } \\
\hline Live births & 18,607 & 41,187 & 41,786 & 41,731 & 40,687 & 38,404 & 40,703 & 41,206 & 39,779 & 344,090 \\
\hline Screened children & 2304 & 1450 & 3095 & 686 & 2616 & 3269 & 461 & 6302 & 2819 & 23,002 \\
\hline Coverage (\%) & 12.4 & 3.5 & 7.4 & 1.6 & 6.4 & 8.5 & 1.1 & 15.3 & 7.1 & 6.7 \\
\hline \multicolumn{11}{|c|}{ SCREENING } \\
\hline Positive children & 11 & 5 & 22 & 2 & 6 & 4 & 1 & 25 & 11 & 87 \\
\hline Recall success rate (\%) & 0.5 & 0.3 & 0.7 & 0.3 & 0.2 & 0.1 & 0.2 & 0.4 & 0.4 & 0.4 \\
\hline $\begin{array}{c}\text { False-positive } \\
\text { (Second screening) }\end{array}$ & 7 & 2 & 18 & 2 & 3 & - & 1 & 15 & 10 & 58 \\
\hline False-positive (\%) & 63.6 & 40 & 81.8 & 100 & 50 & - & 100 & 60 & 91 & 66.7 \\
\hline Inadequate samples ${ }^{1}$ & 121 & 63 & 119 & 22 & 84 & 97 & 9 & 122 & 44 & 681 \\
\hline Inadequate samples (\%) & 5.3 & 4.3 & 3.8 & 3.2 & 3.2 & 3.0 & 2.0 & 1.9 & 1.6 & 3.0 \\
\hline \multicolumn{11}{|c|}{ CONFIRMATION } \\
\hline $\begin{array}{l}\text { Confirmed children } \\
\text { with } \mathrm{CH}^{2}\end{array}$ & 4 & 3 & 4 & - & 3 & 4 & - & 10 & 1 & 29 \\
\hline Recall success rate $(\%)^{3}$ & 36.4 & 60 & 18.2 & - & 50.0 & 100 & - & 40 & 9.1 & 33.3 \\
\hline $\begin{array}{l}\text { Children with } \\
\text { permanent } \mathrm{CH}\end{array}$ & 1 & - & 1 & - & 1 & 2 & - & 5 & 1 & 11 \\
\hline $\begin{array}{l}\text { Children with } \\
\text { transient } \mathrm{CH}\end{array}$ & 2 & 2 & 2 & - & 1 & 2 & - & 4 & - & 13 \\
\hline $\begin{array}{c}\text { False-positive } \\
\text { (Confirmation for } \mathrm{CH} \text { ) }\end{array}$ & 1 & 1 & 1 & - & 1 & - & - & 1 & - & 5 \\
\hline False positive (\%) & 25 & 33.3 & 25 & - & 33.3 & - & - & 10 & - & 17.2 \\
\hline
\end{tabular}

${ }^{1}$ Inadequate sample for TSH determination due to faulty technique in dried blood samples collection, which were determined by the guidance of NBS from IAEA and CDC. ${ }^{2}$ The number sent for confirmation of $\mathrm{CH} .{ }^{3}$ The percentage of children retested in serum for confirmation of $\mathrm{CH}$.

All the positive children at screening $(n=87)$ were recalled for second screening, representing an average recall success rate of $0.4 \%$, a value in accordance with international standards for TSH-based screenings [14]. From these infants, only 29 were sent for 
confirmation of $\mathrm{CH}$, whereas 58 children were false-positive, representing an average of $66.7 \%$ of all positive children.

Finally, 24 of the 29 children were confirmed for primary $\mathrm{CH}$, showing elevated TSH and decreased tT4 for those who were treated with T4 supplementation. We did not determine whether or not these patients had permanent primary hypothyroidism at the screening period. During the study period, the thyroid function of 13 infants (six infants were premature, five infants had intrauterine fetal growth retardation, and two infants had the mother's antithyroid medication effect) normalized within six months of life, and thus, these infants were assumed to have transient $\mathrm{CH}$; the remaining five had false-positive results. Thus, we identified 11 children with permanent $\mathrm{CH}$, and we found that the prevalence of primary $\mathrm{CH}$ was 1 in 2091 in Ulaanbaatar, Mongolia.

Among the identified $\mathrm{CH}$ cases, four cases occurred in males, whereas seven cases were in females. The female-to-male ratio for $\mathrm{CH}$ cases was 1.8:1 in our study. The majority of the children were born by spontaneous vaginal delivery $(72.7 \%$ of $\mathrm{CH}$ cases). The average birth weight was $3856.6 \pm 235.5 \mathrm{~g}$. The average birth height and head circumference were $48.2 \pm 0.3 \mathrm{~cm}$ and $34.3 \pm 1.1 \mathrm{~cm}$, respectively. The median gestational age was 40 ; the range was five weeks. In addition, the average TSH level in dried blood spots was $33.8 \pm 18.9 \mathrm{mIU} / \mathrm{L}$. The median duration of treatment initiation was 15 days.

The majority of patients were asymptomatic (72.7\%). Umbilical hernia and cold or mottled skin were the reported symptoms in our study (27.3\%) (Table 2). Regarding the etiology of $\mathrm{CH}$, a thyroid scan was performed in patients with permanent $\mathrm{CH}$. Thyroid dysgenesis (hypoplasia and agenesis) was the most common etiology, with a total of nine cases (81.8\% of cases) out of the 11 patients. Among them, cysts were found in two patients (18.2\% of cases) with thyroid hypoplasia. Only two (18.2\% of cases) patients had normal thyroid glands (Table 2).

Finally, the lapse between the birth date and the initiation of L-thyroxine treatment in $\mathrm{CH}$-positive children was lower than 15 days in $63.6 \%$ of cases and 15 to 30 days in $36.4 \%$ of children.

Table 2. Clinical manifestations of congenital hypothyroidism at the recall period.

\begin{tabular}{cccc}
\hline Patient & Sex & Clinical Manifestations & Thyroid Ultrasound \\
\hline 1 & F & Cold or mottled skin & Hypoplasia \\
\hline 2 & F & Asymptomatic & Hypoplasia \\
\hline 3 & F & Asymptomatic & Cysts with hypoplasia \\
\hline 4 & M & Asymptomatic & Hypoplasia \\
\hline 5 & F & Asymptomatic & Hypoplasia \\
\hline 6 & F & Asymptomatic & Normal \\
\hline 7 & F & Umbilical Hernia & Cysts with hypoplasia \\
\hline 8 & M & Asymptomatic & Normal \\
\hline 9 & M & Asymptomatic & Hypoplasia \\
\hline 10 & F & Asymptomatic & Hypoplasia \\
\hline 11 & M & Umbilical Hernia & Hypoplasia \\
\hline
\end{tabular}

\section{Discussion}

In most developed countries, NBS is employed as a preventive and public health measure to identify and treat birth defects due to certain congenital conditions [14]. By government support, these developed countries/regions (Korea, Japan, Thailand, Singapore, Australia, New Zealand, and Hong Kong) have succeeded in reaching coverage rates of over $95 \%$ of their newborn population [4,14]. In Mongolia, a neonatal screening program for $\mathrm{CH}$ was started in 2000, the result of an international collaboration with IAEA, which was discontinued due to financial constraints in 2002. 
In the present study, a total of 23,002 newborns (6.7\% of annual births in Ulaanbaatar) were screened between 2012 and 2020 by measurement of the TSH from dried blood spots. Since this screening program was non-governmental, it received economic support from the Science and Technology Fund, Mongolia and Global Grand of Rotary International. The program reached a mean coverage of $6.7 \%$ of neonates born in participating maternity hospitals, increasing from the initial $12.4 \%$ to a maximum of $15.3 \%$. However, our screening coverage was lower than levels of NBS coverage in the most economically developed countries, but many developing countries have only reached less than $1 \%$ of screening coverage due to other forms of infant screening competing with other health priorities, e.g., the control of infectious diseases, immunization, and malnutrition [15,16].

In our study, 24 neonates were confirmed as $\mathrm{CH}$-positive. Of them, 11 neonates were permanent primary $\mathrm{CH}$. This showed the largest national database on newborn screening to investigate an overall prevalence of $\mathrm{CH}$ of 1 per 2091 live births. The overall prevalence of primary $\mathrm{CH}$ in our present study was similar to the estimates of recent studies conducted in Ireland (1:2200) [17], China (1:2278) [12], the United States of America (1:2350) [18], Saudi Arabia (1:2470) [19], and Taiwan (1:1992) [3], However, similar or even higher results were found in Italy (1:1923) [20], Iran (1:1000) [21], Canada (1:1500) [22] and Srilanka (1:1652) [13].

In the first pilot study in Mongolia conducted by Erdenechimeg [8], the frequency of primary $\mathrm{CH}$ was slightly higher (1:1892) than in the present study. However, this pilot study was short term, and the number of participating children was low, which could have led to the conclusion concerning the high frequency of primary $\mathrm{CH}$ in Mongolia.

All countries with a coverage of at least $90 \%$ have fully integrated this screening program into their health delivery systems, including a payment scheme for an NBS fee. Payment is either covered by the government, insurance, or out-of-pocket expenses of the family [15]. However, to date, this health system has not been established in most developing countries, including Mongolia. In regard to the relatively high prevalence of $\mathrm{CH}$ in Mongolia due to not fully undetected risk factors and signs of $\mathrm{CH}$ often being subtle at birth, integration of universal screening programs among newborns into universal health coverage might be an appropriate public health policy option.

Most of the newborns are asymptomatic at birth, and only $5 \%$ to $10 \%$ of affected newborns had clinical signs and symptoms of $\mathrm{CH}$ [23]. More than four to six weeks after birth, children with severe $\mathrm{CH}$ may present with the symptoms and signs of $\mathrm{CH}$, such as poor feeding, constipation, lethargy or excessive sleeping, failure to thrive, large anterior fontanelles, dry skin, prolonged jaundice, mottling, umbilical hernia, macroglossia, or coarse facial features [5]. In our study, most of the patients were asymptomatic $(72.7 \%)$, which was considered slightly lower in comparison to the worldwide prevalence (90 to $95 \%$ are asymptomatic) [13]. In the majority of patients, $\mathrm{CH}$ is caused by an abnormal development of the thyroid gland (thyroid dysgenesis), which accounts for $80 \%$ to $85 \%$ of cases, and the remaining 10 to $15 \%$ of cases are caused by dyshormonogenesis [24]. In the present study, dysgenesis accounted for $81.8 \%$, which was consistent with previous studies [23,25]. The average start of treatment was similar (average of 15.5 days) compared to other countries $[26,27]$.

There were some limitations in the present study. First, due to the limited screening areas, particularly in the remote areas of Mongolia, we cannot determine the prevalence of $\mathrm{CH}$ in the whole country. Second, only 29 neonates out of 87 who tested positive for $\mathrm{CH}$ were retested for confirmation of $\mathrm{CH}$, while 58 neonates were considered as false-positive results by our second screening. According to the guideline of the American Academy of Pediatrics, specimens collected in the first 24 to $48 \mathrm{~h}$ of life may lead to false-positive TSH elevations when using any screening test approach [28].

Therefore, we suspected that false-positive samples could occur due to early screening testing for $\mathrm{CH}$ ( $52.4 \%$ of cases were examined within 24 to $35 \mathrm{~h}$ ) and due to early discharge from mothers who delivered by cesarean section (the majority of the children $(61.5 \%)$ and children were discharged before $48 \mathrm{~h}$ of age). Lastly, we could not cover an adequate number of newborns in the screening program due to financial constraints. 
Consequently, the prevalence reported in our study may be underestimated, which means the true prevalence of $\mathrm{CH}$ in Mongolia could be higher than our estimation. Furthermore, a national NBS information system is needed to improve data, increasing the coverage of screening newborns, because not all areas have fully implemented this program.

\section{Conclusions}

This is the first screening program to detect congenital hypothyroidism in the capital city of Ulaanbaatar, Mongolia. Over the course of eight years of NBS for $\mathrm{CH}$, we covered only $6.7 \%$ of all those born in Ulaanbaatar; if we achieve $100 \%$ coverage of that, we can save around 19 to 20 children annually from mental and physical disabilities caused by $\mathrm{CH}$. Furthermore, as the prevalence of $\mathrm{CH}$ seems to be increasing in the Mongolian population, future screening efforts should concentrate on expanding the coverage of the screening to the whole country.

Author Contributions: Conceptualization and methodology, all authors; writing—original draft preparation, A.T., K.B. and T.M.; writing-review and editing, A.T., K.B., T.M., N.K., G.N., O.-E.B., S.N., G.Z., E.G.; statistical analyses A.T., T.M.; project administration, S.N., G.Z., E.G. All authors have read and agreed to the published version of the manuscript.

Funding: This study was partially supported by Science and Technology Fund, Mongolia (grant number 42/11a123, 2012-2015); Rotary club of Niislel, Mongolia, Rotary club of Yongin, Korea, Rotary International Global Grand (grant number GG1527599, 2014-2019) and Rotary club of Niislel, Mongolia, Rotary club of Yongin, Korea, Global Grand of Rotary International (grant numbers GG 1978569, 2018-2020). The authors confirm that the sponsors had no role in the study; the content of the article was not influenced by the sponsors.

Institutional Review Board Statement: The study was conducted according to the guidelines of the Declaration of Helsinki and approved by the Medical Ethics Review Committee of the Ministry of Health (23 May 2012, No. 2); the Medical Ethics Review Subcommittee of the Mongolian National University of Medical Sciences (17 January 2020, No. 2020/3-01); the National Center for Maternal and Child Health (6 May 2015, No. 359); and the Screening Diagnostic Reference Center, Mongolia (19 January 2015, No. 01).

Informed Consent Statement: Informed consent was obtained from all subjects involved in the study. Written informed consent has been obtained from the patient(s) to publish this paper.

Data Availability Statement: The data presented are available upon request from the corresponding author. The data are not publicly available because of privacy restrictions.

Acknowledgments: We thank those who worked with us for Neonatal Screening in Mongolia, such as Newborn Screening Team Mongolia, who are working at the Urguu, Khuree and Amgalan maternity hospitals, Intermed international hospital, Gurvan Gal hospital and Tanii Tuluu Bid hospital, Screening Diagnostic Reference Center, National Center for Maternal and Child Health, Mongolian National University of Medical Science, who supported our finance, such as the Science and Technology Fund, Mongolia; Rotary International Global Grand, Rotary club of Yongin, Korea; Rotary club of Niislel, Mongolia and who helped us sincerely Pribory Oy, Perkin Elmer lnc, Turku, Finland; UNFPA Mongolia.

Conflicts of Interest: The authors declare no conflict of interest.

\section{References}

1. Büyükgebiz, A. Newborn screening for congenital hypothyroidism. J. Clin. Res. Pediatr. Endocrinol. 2013, 5 (Suppl. 1), 8-12. [CrossRef]

2. Di Cosmo, C.; Tonacchera, M. Congenital Hypothyroidism. In Thyroid Diseases: Pathogenesis, Diagnosis and Treatment; Vitti, P., Hegedus, L., Eds.; Springer International Publishing: Cham, Switzerland, 2018. [CrossRef]

3. Chen, C.-Y.; Lee, K.-T.; Lee, C.T.-C.; Lai, W.-T.; Huang, Y.-B. Epidemiology and Clinical Characteristics of Congenital Hypothyroidism in an Asian Population: A Nationwide Population-Based Study. J. Epidemiol. 2013, 23, 85-94. [CrossRef] [PubMed]

4. Kopel, J. A global perspective on newborn congenital hypothyroidism screening. Proc. Baylor Univ. Med. Center 2019, 33, 137-139. [CrossRef] [PubMed] 
5. Al Jafari, M.; Jose, S.; Al Senani, A. Demographic Features and Etiology of Congenital Hypothyroidism at the National Diabetes and Endocrine Center in Oman from 2004 to 2016. Oman Med. J. 2020, 35, e171. [CrossRef] [PubMed]

6. Ford, G.; LaFranchi, S.H. Screening for congenital hypothyroidism: A worldwide view of strategies. Best Pract. Res. Clin. Endocrinol. Metab. 2014, 28, 175-187. [CrossRef] [PubMed]

7. Léger, J. Congenital hypothyroidism: A clinical update of long-term outcome in young adults. Eur. J. Endocrinol. 2015, 172, R67-R77. [CrossRef] [PubMed]

8. Erdenechimeg, S. National neonatal hypothyroid screening program in Mongolia. Southeast Asian J. Trop Med. Public. Health 2003, 34 (Suppl. 3), 85-86.

9. International Atomic Energy Agency. Screening of Newborns for Congenital Hypothyroidism; International Atomic Energy Agency: Vienna, Austria, 2006.

10. Centers for Disease Control and Prevention (CDC). Guide for Receiving and Storing Dried Blood Spots (DBS) for Molecular Testing at Reference Laboratories; Centers for Disease Control and Prevention (CDC): Atlanta, GA, USA, 2018.

11. Anastasovska, V.; Sukarova-Angelovska, E.; Pesevska, M.; Taseva, E.; Kocova, M. Regional Variation in the Incidence of Congenital Hypothyroidism in Macedonia. Int. J. Neonat. Screen 2017, 3, 22. [CrossRef]

12. Deng, K.; He, C.; Zhu, J.; Liang, J.; Li, X.; Xie, X.; Yu, P.; Li, N.; Li, Q.; Wang, Y. Incidence of congenital hypothyroidism in China: Data from the national newborn screening program, 2013-2015. J. Pediatr. Endocrinol. Metab. 2018, 31, 601-608. [CrossRef]

13. Mehran, L.; Khalili, D.; Yarahmadi, S.; Amouzegar, A.; Mojarrad, M.; Ajang, N.; Azizi, F. Worldwide Recall Rate in Newborn Screening Programs for Congenital Hypothyroidism. Int. J. Endocrinol. Metab. 2017, 15, e55451. [CrossRef]

14. Van Trotsenburg, P.; Stoupa, A.; Léger, J.; Rohrer, T.; Peters, C.; Fugazzola, L.; Cassio, A.; Heinrichs, C.; Beauloye, V.; Pohlenz, J.; et al. Congenital Hypothyroidism: A 2020-2021 Consensus Guidelines Update-An ENDO-European Reference Network Initiative Endorsed by the European Society for Pediatric Endocrinology and the European Society for Endocrinology. Thyroid 2021, 31, 387-419. [CrossRef]

15. Padilla, C.D. Towards universal newborn screening in developing countries: Obstacles and the way forward. Ann. Acad. Med. Singap 2008, 37, 6-9.

16. Therrell, B.L., Jr.; Padilla, C.D. Newborn screening in the developing countries. Curr. Opin. Pediatr. 2018, 30, 734-739. [CrossRef] [PubMed]

17. McGrath, N.; Hawkes, C.P.; McDonnell, C.M.; Cody, D.; O'Connell, S.M.; Mayne, P.D.; Murphy, N.P. Incidence of Congenital Hypothyroidism Over 37 Years in Ireland. Pediatrics 2018, 142. [CrossRef]

18. Kilberg, M.J.; Rasooly, I.R.; LaFranchi, S.H.; Bauer, A.J.; Hawkes, C.P. Newborn Screening in the US May Miss Mild Persistent Hypothyroidism. J. Pediatr. 2018, 192, 204-208. [CrossRef]

19. Shaikh, A.A.; Alsofyani, A.; Shirah, B.; Noaim, K.A.; Ahmed, M.E.; Babiker, A.; Alwan, I.A. Congenital hypothyroidism in Saudi population in two major cities: A retrospective study on prevalence and therapeutic outcomes. Int. J. Health Sci. 2021, 15, 17-21.

20. Olivieri, A.; Fazzini, C.; Medda, E. Multiple factors influencing the incidence of congenital hypothyroidism detected by neonatal screening. Horm Res. Paediatr. 2015, 83, 86-93. [CrossRef]

21. Rahmani, K.; Yarahmadi, S.; Etemad, K.; Mehrabi, Y.; Aghang, N.; Koosha, A.; Soori, H. Intelligence Quotient at the Age of Six years of Iranian Children with Congenital Hypothyroidism. Indian Pediatr. 2018, 55, 121-124. [CrossRef] [PubMed]

22. Saleh, D.S.; Lawrence, S.; Geraghty, M.T.; Gallego, P.H.; McAssey, K.; Wherrett, D.K.; Chakraborty, P. Prediction of congenital hypothyroidism based on initial screening thyroid-stimulating-hormone. BMC Pediatr. 2016, 16, 24. [CrossRef] [PubMed]

23. Szinnai, G. Genetics of normal and abnormal thyroid development in humans. Best Pract. Res. Clin. Endocrinol. Metab. 2014, 28, 133-150. [CrossRef]

24. Sun, F.; Zhang, J.X.; Yang, C.Y.; Gao, G.Q.; Zhu, W.B.; Han, B.; Zhang, L.L.; Wan, Y.Y.; Ye, X.P.; Ma, Y.R.; et al. The genetic characteristics of congenital hypothyroidism in China by comprehensive screening of 21 candidate genes. Eur. J. Endocrinol. 2018, 178, 623-633. [CrossRef] [PubMed]

25. Mio, C.; Grani, G.; Durante, C.; Damante, G. Molecular defects in thyroid dysgenesis. Clin. Genet. 2020, 97, 222-231. [CrossRef] [PubMed]

26. Mansour, C.; Ouarezki, Y.; Jones, J.; Fitch, M.; Smith, S.; Mason, A.; Donaldson, M. Trends in Scottish newborn screening programme for congenital hypothyroidism 1980-2014: Strategies for reducing age at notification after initial and repeat sampling. Arch Dis. Child 2017, 102, 936-941. [CrossRef] [PubMed]

27. Nanu, M.; Ardeleanu, I.S.; Brezan, F.; Nanu, I.; Apostol, A.; Moldovanu, F.; Lazarescu, H.; Gheorghiu, M.L.; Kozma, A. Neonatal Screening for Congenital Hypothyroidism In Romania: Data From Medilog Medical Information Registry. Acta Endocrinol. 2019, 15, 209-214. [CrossRef]

28. Rose, S.R.; Brown, R.S.; Foley, T.; Kaplowitz, P.B.; Kaye, C.I.; Sundararajan, S.; Varma, S.K. Update of newborn screening and therapy for congenital hypothyroidism. Pediatrics 2006, 117, 2290-2303. [CrossRef] [PubMed] 